only for multiple myeloma. Moreover, as the authors acknowledge, analyses of various cohorts of radiation workers (which overlap in part with the cohort studied by Kneale and Stewart) in the United States and elsewhere ${ }^{34}$ find no evidence of statistical incompatibility between the cancer risks associated with such occupational exposure and those found in the survivors of the Japanese atomic bombs. ${ }^{6}$ Consequently, we think that little weight should be attached to the results of the paper of Kneale and Stewart.

MARK LITTLE CHRIS SHARP Medical Department National Radiological Protection Board Chilton, Didcot OX11 ORQ

1 Kneale GW, Stewart AM. Factors affecting recognition of cancer risks of nuclear workers. Occup Environ Med 1995;52:515-23.

2 Gilbert ES, Omohundro E, Buchanan JA, Holter NA. Mortality of workers at the Hanford

3 Kendall GM, Muirhead CR, MacGibbon BH, et al. Mortality and occupational exposure to et al. Mortality and occupational exposure to
radiation: first analysis of the National radiation: first analysis of the National
Registry for Radiation Workers. BMf 1992; Registry for
304:220-5.

4 Cardis E, Gilbert ES, Carpenter L, et al. Effects of low doses and low dose rates of external ionizing radiation: cancer mortality among nuclear industry workers in three countries. Radiat Res 1995;142:117-32.

5 Cox DR, Hinkley DV. Theoretical statistics. London: Chapman and Hall, 1974.

6 Shimizu Y, Kato H, Schull WJ. Studies of the mortality of A-bomb survivors. 9. Mortality, 1950-85: Part 2. Cancer mortality based on 1950-85: Part 2. Cancer mortality based on the recently revised

Author's reply-Most of the difficulties which Little and Sharp have with our paper would seem to stem from a failure to understand that our statistical methods were simply practical applications of the general theory of nested likelihood ratio tests. This theory is a very general method of identifying statistical tests that have a wide range of optimum properties provided one has a sufficiently general statistical model of a parametric kind that describes how the data might have been generated, and provided this model satisfies certain easily checkable mathematical restrictions. Why this is so can be discovered in any general text book of mathematical statistics, either the one referenced in our paper-namely, Kendall and Stuart ${ }^{1}$ - or the one preferred by Little and Sharp-namely, Cox and Hinkley. ${ }^{2}$

For studying the relation between radiation and carcinogenesis relevant parametric models can be found in Breslow and Day. ${ }^{3}$ For example, how intuitive ideas about a case-control study can be justified by making use of a parametric model is shown in Vol I page 248, and two formulae for parametric models for cohort studies are given in Vol II page 186. The choice of which formula depends upon whether the cohort study is progressing in continuous time (first formula) or in discrete units of time (second formula). We naturally used the second formula as our radiation doses were only available as annual totals.

The mathematical techniques and limited computer facilities available in 1980 did not allow direct (case-control) methods to be used in cohort studies. Therefore, Vol II of Breslow and Day deals mainly with studies where various approximations (such as Poisson regression when person-years at risk can be calculated) lead to the standard procedures recommended by Little and Sharp.
But although we made use of the formulae on page 186, our numerical methods (for completing the necessary maximum likelihood calculations) differed from the ones recommended by Breslow and Day over 15 years ago.

If new variations of standard methods were not allowed there would be little progress in science. Nevertheless, as we agree with our critics that any new methodology should have its results checked against standard methods, we included in our paper two tables expressly for this purpose. Thus table 7, which includes the basic nested likelihood ratio tests and parameter estimates by maximum likelihood, shows that the most important of the three extra variables influencing relations between radiation and carcinogenesis was exposure age. This is important because virtually all of our models which had included an optimised minimum value for critical exposure age were significant at the $5 \%$ or $1 \%$ level, whereas the models without an optimised value for this variable had much lower levels of significance. Then comes table 9, which shows the results of testing the null hypothesis of no radiation effect by a method exactly equivalent to the standard one recommended by Little and Sharp, but uses the windowed doses prescribed by optimised values of minimum critical exposure age and minimum critical latency. Consequently the significance levels in this table (which lay between $1 \%$ and $0.1 \%$ ) and which were calculated by the standard formulae, had greater strength than the ones in table 7, as they did not take account of the window restrictions.

It should also be noted that although in two papers which used the standard methods approved by Little and Sharp, ${ }^{45}$ lip service was paid to the idea that latency was important-by lagging for doses at stated intervals - this was a very crude method of estimating optimal latency compared with the one we used.

Having explained the theory behind our methodology, it is time to turn to the more detailed criticisms of the Little and Sharp. It is true that in our analysis the critical minimums for exposure age and latency were confined to values of integral years as, with dose estimates only available for whole years, we were forced to use the discrete time formula of Breslow and Day. However, with maximum likelihood as the method of risk estimation, the integral year estimate would necessarily have a slightly lower maximum than any fractional year estimates for continuous doses. Therefore, as our calculated level of significance was based on integral years, it provided a less rigid test of the null hypothesis than one based on daily or weekly doses, and thus left us "playing safe".

Little and Sharp's criticism of the degrees of freedom estimate for a window which allows a zero estimate of effective dose, shows some confusion in their minds about the standard tabular $\chi^{2}$ (which has many degrees of freedom for testing independence in tabulated data) and the $\chi^{2}$ corresponding to generalised deviance in the nested likelihood ratio theory. The degrees of freedom for this $\chi^{2}$ depend not on the number of cells in some mythical table containing all the relevant data, but on the number of variables being estimated. The situation is exactly analogous to the formulae used by Gilbert $e t$ $a l^{4}$ and Cardis et $a l^{5}$ for calculating the significance of their results based on lagged dose estimates. By this method some workers with recorded doses were left with an effective dose of zero. But this no more altered the approximate normal distribution of their test statistic, than it would have altered the approximate $\chi^{2}$ distribution arising in the nested likelihood ratio theory.

Finally, for anyone interested in this arena of statistical theory, it may be of interest to know that the theory of nested likelihood ratio tests was discovered by combining the standard (tabular) $\chi^{2}$ with the standard analysis of variance ratio of $\chi^{2} s$, and that was how $\chi^{2}$ came to be relevant. All this can be investigated either in Kendall and Stuart or in Cox and Hinkley.

GEORGE W KNEALE ALICE M STEWART

Department of Public Health and Epidemiology, University of Birmingham,

1 Kendall MG, Stuart A. The advanced theory of statistics. Vol 1-3. London: Charles Griffin, 1963.

2 Cox DR, Hinkley DV. Theoretical statistics. London: Chapman and Hall, 1964.

3 Breslow NE, Day NE. Statistical methods in cancer research. Vol I. The analysis of casecontrol studies. Vol II. The design and analysis of cohort studies. LARC Sci Publ 1980;32:186.

4 Gilbert ES, Omohundro E, Buchanan JA, Holter NA. Mortality of workers at the Hanford site: 1945-86. Health Phys 1993;64: 577-90.

5 Cardis E, Gilbert ES, Carpenter L, et al. Effects of low doses and low dose rates of external ionizing radiation: cancer mortality among nuclear industry workers in three among nuclear industry workers in

Parental exposure to radiation and childhood cancer

This study ${ }^{1}$ was referred to by Roman et al (p 78) as a "study linking dosimetry information contained within the National Registry of Radiation Workers (NRRW) with records of childhood cancer held in the National Registry of Childhood Tumours (NRCT)". This statement needs amplification. From the outset, the Oxford Survey of Childhood Cancers (OSCC) has been a partner in this project. Identifying particulars for some 40000 parents have been abstracted from the interview records of the OSCC; these data are not contained within the files of the National Registry of Childhood Tumours.

TOM SORAHAN University of Birmingham, Institute of Occupational Health, Edgbaston, Birmingham B13 2TT

1 Kendall GM, Muirhead CR, Draper GJ. Parental exposure to radiation and childhood cancer. Radiological Protection Bulletin 1993, 147:7-13.

2 Eve Roman, Pat Doyle, Pat Ansell, Diana Bull, Valerie Beral. Health of children born to medical radiographers. Occup Environ Med 1996;53:73-9.

\section{Offspring sex ratio as an indicator of reproductive hazards}

Editor-In a recent letter the sex ratio was discussed as an indicator of occupational exposures. ${ }^{12}$

The sex ratio at birth is a prevalence measure reflecting the sex programming at the time of conception and the survival until birth. The sex ratio has been suggested to reflect the hormone concentration at the time of conception. ${ }^{134}$ According to this hypothesis high levels of gonadotropin changes the ratio towards more girls. External exposures may have this effect as 
well as endogenous factors such as obesity or hormonal disorders.

A conception closely associated in time with ovulation has been suggested to result in more boys. ${ }^{5} \mathrm{~A}$ high frequency of sexual intercourse should, according to this hypothesis, lead to a predominance of boys and a decline in the sex ratio according to age or parity could reflect a decline in sexual activity by age or a change in endogenous hormones over time. ${ }^{6} \mathrm{~A}$ low frequency could furthermore lead to low fecundity.

A recent study showed that conception cycles with a short follicular phase produced more boys than girls. ${ }^{7}$ Exposures like dibromochloropropane (DBCP) have been shown to be associated with both low fecundity and a low sex ratio. ${ }^{2}$ De Cock et al found a difference in the time to pregnancy for boys and girls with the shortest time to pregnancy for the boys. ${ }^{8}$ These observations indicate a link between fecundity as measured by time to pregnancy and sex ratio.

Based upon these observations we report data on sex ratio (measured as the proportion of boys among all newborns). It was expected that the sex ratio would decline with body mass index, age, parity, and low fecundity.

The analyses are based upon data from a community trial named "Healthy habits for two" conducted between 1984 and 1987. All pregnant women in the Danish cities Odense and Aalborg were asked to give detailed information on lifestyle factors during pregnancy and obstetrical information on delivery was recorded from the medical files. ${ }^{9}$ The study subjects constituted 10042 pregnant women (singletons only) after excluding 1808 women $(15.26 \%)$ with incomplete data.

The participants delivered 5137 boys and 4905 girls (sex ratio $=0.51$ ). Table 1 shows a weak but not significant trend towards a lower sex ratio with increasing age (except

Table 1 Maternal characteristics and sex ratio of offspring

\begin{tabular}{|c|c|c|c|}
\hline & Sex ratio & $\begin{array}{l}\text { Offspring } \\
\text { (n) }\end{array}$ & $\begin{array}{l}P \text { value } \\
\text { ( } \chi^{2} \text { test } \\
\text { for trend) }\end{array}$ \\
\hline \multicolumn{4}{|l|}{ Maternal age: } \\
\hline $15-19$ & 0.483 & 259 & \\
\hline $20-24$ & 0.522 & 2652 & \\
\hline $25-29$ & 0.510 & 4307 & \\
\hline $30-34$ & 0.510 & 2123 & \\
\hline $35-39$ & 0.493 & 629 & \\
\hline $40-45$ & 0.542 & 72 & 0.480 \\
\hline \multicolumn{4}{|c|}{$\begin{array}{l}\text { Maternal body mass index } \\
\left(\mathrm{kg} / \mathrm{m}^{2}\right):\end{array}$} \\
\hline $15-19$ & 0.502 & 3084 & \\
\hline $20-24$ & 0.517 & 5705 & \\
\hline $25-29$ & 0.512 & 970 & \\
\hline$>30$ & 0.502 & 283 & 0.462 \\
\hline \multicolumn{4}{|l|}{ Maternal parity: } \\
\hline 0 & 0.515 & 4899 & \\
\hline 1 & 0.511 & 3867 & \\
\hline 2 & 0.500 & 1060 & \\
\hline $3-5$ & $0 \cdot 486$ & 216 & $0 \cdot 263$ \\
\hline
\end{tabular}

Table 2 Time to pregnancy and sex ratio at birth

\begin{tabular}{lclll}
\hline $\begin{array}{l}\text { Time to } \\
\text { pregnancy }\end{array}$ & $\begin{array}{l}\text { Boy } \\
(n)\end{array}$ & $\begin{array}{l}\text { Girl } \\
(n)\end{array}$ & $\begin{array}{l}\text { Sex } \\
\text { ratio }\end{array}$ & $\begin{array}{l}\text { Pvalue } \\
\chi^{2} \text { test }\end{array}$ \\
\hline $0-6$ months & 3788 & 3528 & 0.518 \\
$7-12$ months & 479 & 449 & 0.516 & \\
$>1 \mathrm{y}$ & 870 & 928 & 0.484 & $\mathrm{P}=0.035$ \\
\hline \multicolumn{7}{l}{ Test for trend: sex ratio $\mathrm{P}=0.015$}
\end{tabular}

for women over 40 years of age) and increasing parity. No association was found between body mass index and the sex ratio.

The only significant association was a lower sex ratio among couples with a time to pregnancy of more than 12 months (table $2)$. After entering all the variables into a logistic regression model with the sex ratio as the outcome only infertility remained significantly associated with a low sex ratio with an odds ratio (OR) for having a boy of 0.874 (95\% confidence interval (95\% CI) 0.789 to 0.968 ).

The reason for the low sex ratio in some couples with low fecundity could be due to the same hormonal imbalance that causes the infertility or low sexual activity in couples who can be treated by hormones. Future studies should be able to discriminate between these possible factors.

ZHOU WEIJIN

The Danish Epidemiology Science Centre,

The Steno Institute of Public Health,

University of Aarhus, DK-8000 Aarhus C, Denmark

1 James WH. Sex ratio of offspring as a criterion of occupational hazard, with reference to welding [letter]. Scand $\mathcal{f}$ Work Environ Health 1994;20:466-7.

2 James WH. Offspring sex ratio as an indicator of reproductive hazards associated with pesticides [letter]. Occup Environ Med 1995;52: 429.

3 James WH. The human sex ratio. Part 2: a hypothesis and a program of research. Hum Biol 1987;59:873-900.

4 James WH. The hypothesized hormonal control of sex ratio at birth-a second update. $\mathcal{F}$ Theor Biol 1992;155:121-8.

5 France JT, Graham FM, Gosling L, Hair P, Knox BS. Characteristics of natural conceptual cycles occurring in a prospective study of sex preselection: fertility awareness symptoms, hormone levels, sperm survival, and pregnancy outcome. Int $\mathcal{f}$ Fertil 1992;37: 244-55.

6 James WH. Cycle day of insemination, coital rate, and sex ratio. Lancet $1971 ; 16: 112-4$

7 Weinberg CR, Baird DD, Wilcox AJ. The sex of the baby may be related to the length of the follicular phase in the conception cycle. Hum Reprod 1995;10:304-7.

8 De Cock J, Heederik D, Tielemans E, Te Velde E, Van Kooij R. Offspring sex ratio as an indicator of reproductive hazards associated with pesticides [author's reply]. Occup Environ Med 1995;52:429-30.

9 Olsen J, Frische G, Poulsen AO, Kirchheiner $\mathrm{H}$. Changing smoking, drinking, and eating behaviour among pregnant women in Denmark. Scand $\mathcal{F}$ Soc Med 1989;17:277-80.

\section{BOOK REVIEW}

Book review editor: R L Maynard

If you wish to order, or require further information regarding the titles reviewed here, please write or telephone the BMJ Bookshop, PO Box 295, London WX1H 9TE. Tel: 0171383 6244. Fax: 0171383 6662 . Books are supplied post free in the UK and for British Forces Posted Overseas addresses. Overseas customers should add $15 \%$ for postage and packing. Payment can be made by cheque in sterling drawn on a UK bank, or by credit card (MasterCard, VISA, or American Express) stating card number, expiry date, and your full name. (The price and availability are occasionally subject to revision by the Publishers.)
CRC Handbook of Chemistry and Physics, 76th edition. Edited by DAVID R LIDE. (Price f79.) 1995. Boca Raton, Florida: CRC Press. ISBN 0-8493-0476-8.

Some years ago, I mused on a never submitted idea for a cartoon involving a smart alec child, obviously too clever by half, looking up at one of those kiosks which helpfully promise "Information" and asking the aghast attendant "OK, what's the half life of the pi-meson then?". The CRC Handbook-known to generations of undergraduates simply as the "Rubber Bible"has the answer to this and countless other questions. The fact that it is in its 76 th edition is testimony to the book's usefulness. It is comprehensive, covering just about every area of chemistry and physics that the practising scientist would need. There are chapters ranging from basic constants and units through to biochemistry, passing on the way sections including structural formulae and physical properties of all those organic molecules you thought you'd forgotten, including pesticides and steroid hormones, in an exhaustive list usefully cross referenced by name and synonym index.

The chapter list is impressive-Basic constants, units, and conversion factors, symbols terminology and nomenclature, physical constants of organic compounds, properties of the elements and inorganic compounds, thermochemistry, electrochemistry, and kinetics, fluid properties, biochemistry, analytical chemistry, molecular structure, and spectroscopy, atomic molecular and optical physics, nuclear and particle physics, properties of solids, polymer properties, practical laboratory data, health and safety informa tion, and an appendix of mathematical tables (up to the level of Bessel functions and statistical tables).

Any such compilation must score highly on two counts to be a credible reference book. It must be comprehensive, and the chapter list above is ample demonstration of that. It also has to be accurate and up to date. The list of contributors is extensive, and if those areas where I might have some competence to judge is anything to go by, it also looks of high quality. References are up to date and although the information in such a volume could never replace fully that obtainable from specialist reviews, it is still comprehensive enough and accurate enough to fully justify its reputation as the leading reference work of its kind, and one which no scientific organisation should be without.

As well as in the quality of content and its usefulness in day to day reference, any great reference book also repays moments of idle browsing with the odd gem or two. Did you know that there are $10^{8}$ shakes in a second? Question the precision therefore of the watch of the next person who offers to see you in a couple of these time units. If despite your better judgement as a trained scientist, you still cling to recipes which cal for such apparently ill defined quantities as "tablespoon" and "teaspoon", worry no more. The "Rubber Bible" has definitions, to three decimal places, of each in metric equivalents.

All in all, a work of reference which should be within 10 feet of any self respecting practising scientist. Or would you like that in parsecs?

M L WILLIAMS 